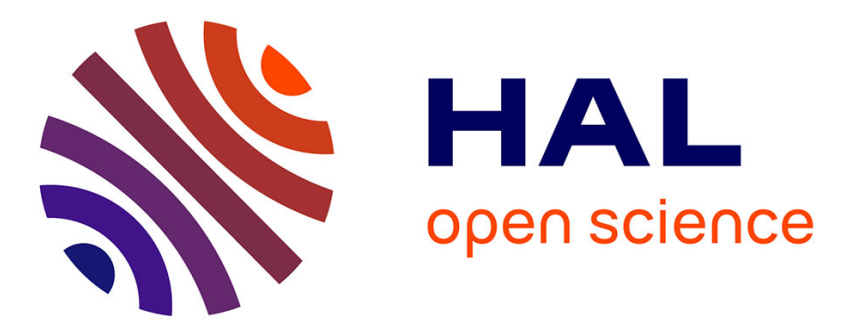

\title{
100-W-level single-mode ytterbium-free erbium fiber
} laser

Louis-Charles Michaud, Catherine Veilleux, Guillaume Bilodeau, Olivier Gilbert-Paquet, Marie-Anne Lebel-Cormier, Maxime Lemieux-Tanguay, Samantha Pelletier-Ouellet, Pascal Paradis, Matthieu Bellec, Nicolas Grégoire, et al.

\section{To cite this version:}

Louis-Charles Michaud, Catherine Veilleux, Guillaume Bilodeau, Olivier Gilbert-Paquet, Marie-Anne Lebel-Cormier, et al.. 100-W-level single-mode ytterbium-free erbium fiber laser. Optics Letters, 2021, 46 (10), pp.2553. 10.1364/OL.427291 . hal-03381860

\section{HAL Id: hal-03381860 https://hal.science/hal-03381860}

Submitted on 18 Oct 2021

HAL is a multi-disciplinary open access archive for the deposit and dissemination of scientific research documents, whether they are published or not. The documents may come from teaching and research institutions in France or abroad, or from public or private research centers.
L'archive ouverte pluridisciplinaire $\mathbf{H A L}$, est destinée au dépôt et à la diffusion de documents scientifiques de niveau recherche, publiés ou non, émanant des établissements d'enseignement et de recherche français ou étrangers, des laboratoires publics ou privés. 


\title{
100-W-level single-mode ytterbium-free erbium fiber laser
}

\author{
Louis-Charles Michaud, ${ }^{1,2, \dagger, *}$ (1) Catherine VeilleuX, ${ }^{1,2, \dagger}$ Guillaume Bilodeau, ${ }^{1,2}$ (1) \\ Olivier Gilbert-Paquet, ${ }^{1,2}$ Marie-Anne Lebel-Cormier, ${ }^{2,3,4}$ Maxime LemieuX-Tanguay, ${ }^{1,2}$ \\ Samantha Pelletier-Ouellet, ${ }^{2}$ Pascal Paradis, ${ }^{1,2}$ (i) Matthieu Bellec, ${ }^{1}$ (1) \\ Nicolas Grégoire, ${ }^{1}$ Steeve Morency, ${ }^{1}$ Younès MessaddeQ, ${ }^{1,2}$ and Martin Bernier ${ }^{1,2}$
}

\author{
${ }^{1}$ Centre d'Optique, Photonique et Laser (COPL), Université Laval, Québec, G1V OA6, Canada \\ ${ }^{2}$ Département de Physique, de Génie Physique et d'Optique, Université Laval, Québec, G1V 0A6, Canada \\ ${ }^{3}$ Centre de Recherche sur le Cancer, Université Laval, Québec, G1R 3S3, Canada \\ ${ }^{4} \mathrm{CHU}$ de Québec, Université Laval et CRCHU de Québec, Québec, G1R2J6, Canada \\ ${ }^{*}$ Corresponding author: louis-charles.michaud.1@ulaval.ca
}

Received 9 April 2021; revised 4 May 2021; accepted 4 May 2021; posted 5 May 2021 (Doc. ID 427291); published 14 May 2021

We report on an ytterbium-free, erbium-doped single-mode all-fiber laser reaching a record output power of $107 \mathrm{~W}$ at $1598 \mathrm{~nm}$, with a slope efficiency of $38.6 \%$ according to the absorbed pump power at $981 \mathrm{~nm}$. The erbium-doped gain fiber, co-doped with cerium, aluminum, and phosphorus, was fabricated in-house with adjusted doping concentrations to reduce erbium ions clustering, thereby increasing efficiency while keeping the numerical aperture low to ensure a single-mode laser operation. The addition of cerium co-dopant in the core glass of an erbium system is used for the first time, to the best of our knowledge, in order to adjust the fiber's numerical aperture without increasing the erbium concentration. Numerical modeling, validated by the experimental results, demonstrates that adding aluminum and phosphorus at high concentration mitigates erbium ions clustering, with an estimated erbium paired ions of only 5.0\% in the reported gain fiber. (๑) 2021 Optical Society of America

https://doi.org/10.1364/OL.427291

Erbium-doped fiber lasers and amplifiers have been studied and used extensively, especially around the 1.5 to $1.7 \mu \mathrm{m}$ emission range. Since this region of the electromagnetic spectrum corresponds to the lowest losses in silica fibers as well as being "eye-safe" [1], they are of particular interest in telecommunications [2] and a number of other applications such as light detection and ranging (LIDAR) [3], gas monitoring [4], and laser pumping [5]. Moreover, single-mode all-fiber lasers operating at high power are also of great interest for material's laser processing given their robustness, reliability, compact design, and excellent beam quality.

One area of research in erbium-doped fiber development has been on increasing the pump absorption to improve the laser efficiency according to the launched pump power and reduce the cavity's length. Such an approach involved adding ytterbium as a co-dopant. Jeong et al. demonstrated an erbium-ytterbium co-doped fiber laser operating at $1565 \mathrm{~nm}$, reaching $297 \mathrm{~W}$ of laser power with respect to the $975 \mathrm{~nm}$ pump power [6]. However, the $\mathrm{M}^{2}$ value of 3.9 shows a multimode operation, and the parasitic ytterbium lasing limited its efficiency at 19\% for high pump powers. Very recent results published by Yu et al. [7] demonstrated the same behavior of laser efficiency saturation at high power from an $\mathrm{Er}-\mathrm{Yb}$ co-doped fiber laser pumped near 1 micron, therefore limiting the power scalability of such approach. Jebali et al. also presented a high power laser using an $\mathrm{Er}-\mathrm{Yb}$ co-doped fiber, making use of the in-band pumping at $1535 \mathrm{~nm}$ [8]. They were able to achieve up to $264 \mathrm{~W}$ of output power with $74 \%$ laser efficiency, although they utilized a complex pumping scheme necessitating 36 combined $14 \mathrm{~W}$ fiber lasers. Nevertheless, ytterbium has the effect of increasing the refractive index of the core, meaning that its diameter needs to be decreased to stay in a single-mode regime. Additionally, the $1 \mu \mathrm{m}$ parasitic emission of this co-dopant is also hazardous to the human eye and optical devices, which makes it beneficial to avoid its use [1].

Because of these drawbacks, the development of high-power sources without the use of ytterbium as a co-dopant remains of great interest. To date, the highest power achieved for an erbium fiber laser was reported in 2018 by Lin $e t$ al. [9]. They demonstrated up to $656 \mathrm{~W}$ of laser power at $1601 \mathrm{~nm}$ using an $\mathrm{Yb}$-free fiber laser cavity with a 35.6\% efficiency. However, the setup used free-space elements, and the laser was strongly multimode and, therefore, had a poor beam quality $\left(\mathrm{M}^{2}=10.5\right)$. Kotov et al. also reported a $75 \mathrm{~W}$ erbium-doped fiber laser free of ytterbium [10] and a $100 \mathrm{~W}$ erbium fiber amplifier [11]. In both cases, they used a square-shaped fiber co-doped with fluorine with a slightly multimode large core requiring induced bending losses to ensure a single-mode operation.

One of the common trade-offs in erbium-doped fiber lasers is the compromise between pump absorption and the occurrence of clustering when the concentration of the erbium ions is increased. One way of reducing the erbium clustering at high concentration is adding co-dopants such as aluminum and phosphorus [12]. In equimolar concentrations, these ions combine into $\mathrm{AlPO}_{4}$ structures, which reduces the occurrence 
of clustering and, therefore, increases the conversion of the pump power into the laser signal. The great advantage of this co-doping approach is that $\mathrm{AlPO}_{4}$ structures have a very similar refractive index compared to silica, which implies that a large amount of co-dopants can be added to the glass matrix without significantly increasing the fiber's numerical aperture [13]. The first demonstration of a co-doped Er-AlPO 4 laser free of ytterbium was presented by Kotov et al. [14]. They achieved up to $7.5 \mathrm{~W}$ of output power, yielding an efficiency of $40 \%$ with respect to the $976 \mathrm{~nm}$ launched pump power. Although this demonstration highlights a very efficient all-fiber laser configuration, the squared fiber design with an $80 \mu \mathrm{m}$ diameter is not practical for pumping with conventional diodes pigtailed with 125 microns fibers. Last year, we demonstrated an all-fiber erbium laser co-doped with aluminophosphosilicate (APS) [13]. This laser reached $25 \mathrm{~W}$ of output power and was built with a standard step-index fiber having a standard cladding diameter of $125 \mu \mathrm{m}$.

Other co-dopants have also been investigated to increase laser efficiency by reducing undesired effects that are preventing the conversion of pump power into laser signal. For example, rare-earth-doped fibers can be co-doped with cerium to mitigate photodarkening losses that reduces the laser efficiency for long term operation at high power, especially in ytterbium-doped fiber lasers where the problem is most prevalent $[15,16]$. It was recently shown that 1.55 micron $\mathrm{Er}-\mathrm{Yb}$ fiber lasers operating at high power can also suffer from photodarkening losses at high power [17]. Cerium also has the effect of increasing the refractive index of the glass matrix.

In this paper, we report an ytterbium-free erbium APS fiber laser co-doped with cerium. The performances of this fiber core composition are demonstrated through the implementation of an all-fiber single-mode laser operating at $1598 \mathrm{~nm}$ using a standard fiber geometry and a pair of intracore fiber Bragg gratings (FBGs) written into a mode-matching passive fiber. The laser cavity reached $107 \mathrm{~W}$ of output power with a single-mode beam quality $\left(\mathrm{M}^{2} \leq 1.12\right)$ when pumped by seven combined laser diodes at $981 \mathrm{~nm}$. The fiber laser yields an efficiency of $38.6 \%$ and $31.2 \%$ according to the absorbed and launched pump powers, respectively. To the best of our knowledge, this is the highest output power achieved from a single-mode Er-doped fiber laser free of ytterbium. It is also the first Er-silica fiber laser co-doped with cerium as far as we know. The numerical modeling confirms that adding aluminum and phosphorus at high concentration mitigates ions clustering with an estimated erbium paired ions of only $5.0 \%$ in our gain fiber.

The preform for the gain fiber was made in-house using the modified chemical vapor deposition (MCVD) technique and solution doping. After collapsing, it was etched in a fluoridric acid bath to achieve the desired cladding to core ratio that optimizes pump absorption while ensuring single-mode operation. The preform was polished from the side in a double $\mathrm{D}$ geometry to prevent the pump propagation of circular modes in the cladding having a poor overlap with the core, thus further improving the pump absorption. Finally, the preform was drawn in a fiber tower at COPL facilities (Laval University) during which a dual polymer coating was applied to the fiber, a first coating of low-index fluoroacrylate with a thickness of 23 microns followed by a second coating of acrylate with a thickness of 37 microns, to achieve a final protected fiber with a standard 250 microns external diameter. The refractive index profile around the fiber core measured with a preform analyzer (Photon Kinetics, model 2610) is shown in Fig. 1 along with the endface of the drawn fiber including its dual polymer.

The parameters of the fiber are compared with our previous work in Table 1. The core glass composition was measured on the preform using an electron microprobe (Cameca SX-100).

The core size of 17.3 microns was chosen to maximize the pump absorption and to ensure a single-mode operation at $1598 \mathrm{~nm}$. Given that $\mathrm{AlPO}_{4}$ formation leads to a near-zero index change compared to silica and given that erbium ions cannot solely be added to the fiber core to adjust the numerical aperture in order to limit ions clustering, cerium ions were added to the core glass matrix to adjust the fiber's numerical aperture to the targeted value of 0.06 . The corresponding single-mode cutoff wavelength of $1409 \mathrm{~nm}$ was measured, ensuring a good confinement of the fundamental mode at the laser wavelength of $1598 \mathrm{~nm}(\mathrm{~V}=2.1)$.

A schematic of the Er-Ce co-doped all-fiber laser is depicted in Fig. 2. Seven $90 \mathrm{~W}$ laser diodes stabilized at $981 \mathrm{~nm}$ (K981ANIRN-90.00W and K981AG1RN-90.00W from BWT) are combined through a $7 \times 1$ high power pump combiner with $105 / 125 \mu \mathrm{m}$ input fibers and a $125 \mu \mathrm{m}$ coreless output fiber (PC623188, Lightel). Such pump combiner was limited to $60 \mathrm{~W}$ per input fiber, thus limiting the maximum
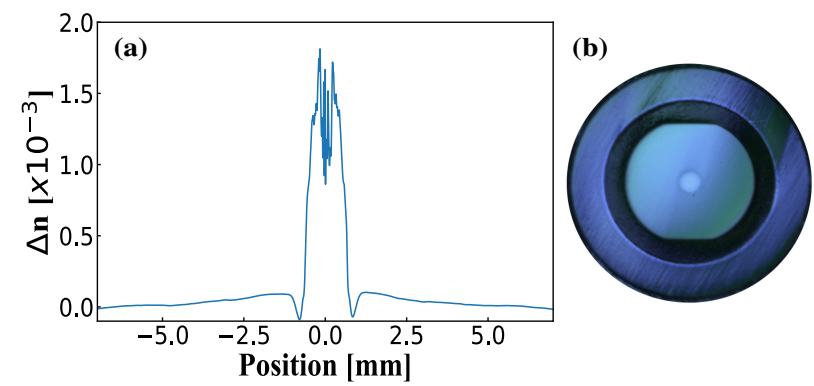

Fig. 1. (a) Change in refractive index in the preform and (b) the endface of the fiber.

Table 1. Properties of the Fiber in This Work Compared to Our Previous Work

\begin{tabular}{lcc}
\hline Parameters & Lord et al. [13] & This Work \\
\hline Core diameter $(\mu \mathrm{m})$ & 17 & 17.3 \\
Cladding diameter $(\mu \mathrm{m})$ & $120 \times 131$ & $121 \times 130$ \\
Numerical aperture & 0.06 & 0.06 \\
Cutoff wavelength $(\mathrm{nm})$ & 1369 & 1409 \\
$\mathrm{Er}_{2} \mathrm{O}_{3}$ (mol.\%) & 0.06 & 0.055 \\
$\mathrm{Ce}_{2} \mathrm{O}_{3}$ (mol.\%) & - & 0.157 \\
$\mathrm{Al}_{2} \mathrm{O}_{3}$ (mol.\%) & 1.77 & 3.85 \\
$\mathrm{P}_{2} \mathrm{O}_{5}$ (mol.\%) & 1.04 & 3.57 \\
Estimated paired ions $(2 \mathrm{k})[\%]$ & 6.3 & 5.0 \\
\hline
\end{tabular}

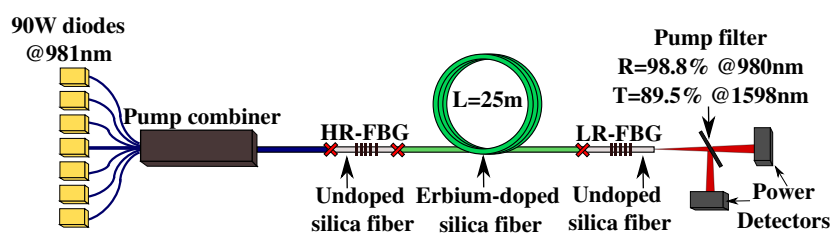

Fig. 2. Schematic of the all-fiber $\mathrm{Er}^{3+}-\mathrm{Ce}^{3+}$-APS laser emitting at $1598 \mathrm{~nm}$. 
input pump power to $420 \mathrm{~W}$. Given the combiner's pump transmission of $94 \%$, and to keep a safe value of input pump power, the maximum launched pump power (after the combiner) was limited to $387 \mathrm{~W}$. The cavity is made of a 25 -m-long Er-Ce co-doped APS fiber and is bounded by a pair of FBGs inscribed in passive fibers to reduce the thermal load. The passive fiber was also fabricated in-house with the same core composition as for the erbium-doped fiber except that erbium was replaced by cerium to obtain the same guiding properties. The FBGs were written at $800 \mathrm{~nm}$ through the polymer coating using the femtosecond phase mask writing technique [18]. The FBGs were thermally annealed to reduce their losses and to stabilize their properties for long-term operation. The splices between the active and passive fibers were monitored to minimize their transmission losses. The output fiber's end is also cleaved at an angle of $6^{\circ}$ to prevent parasitic feedback. A dichroic filter, which is highly reflective at $981 \mathrm{~nm}$, separates the residual pump power from the $1598 \mathrm{~nm}$ signal output to allow the simultaneous measurement of both of them. After testing the cavity at high power, a cladding mode stripper was applied to the delivery fiber to confirm that more than $96 \%$ of the laser signal was guided in the fiber's core The laser characterizations shown in Fig. 4 were corrected according to this value.

The transmission spectra of both FBGs as well as the laser output spectrum at two different output powers are shown in Fig. 3. The high reflectivity (HR) and low reflectivity (LR) FBGs reflect, respectively, $99.8 \%$ and $0.83 \%$ of the signal at $1598 \mathrm{~nm}$. A broadband measurement of the laser output at high dynamic range was performed from $1510 \mathrm{~nm}$ to $1610 \mathrm{~nm}$, and we observed no significant amplified spontaneous emission (ASE). We calculated that more than $99.99 \%$ of the output power is in the main laser peak at $1598 \mathrm{~nm}$.

The laser output power according to both the launched and absorbed pump power at $981 \mathrm{~nm}$ are presented in Fig. 4 where these experimental results are compared to the numerical modeling detailed hereafter.

The slope efficiency according to the absorbed pump power is $38.6 \%$, and the overall efficiency according to the launched pump power is $31.2 \%$. The lower overall efficiency is mainly due to the large amount of residual pump power, up to $87 \mathrm{~W}$ at maximum laser power. The maximum laser output power obtained is $107 \mathrm{~W}$, which is the highest power achieved to date for this laser configuration. Even though Kotov et al. presented a higher overall slope efficiency of $40 \%$ [14], the laser architecture of this work is easier to manufacture due to its robustness and its simple fiber geometry, making it more attractive for industrial laser applications. The efficiency according to launched

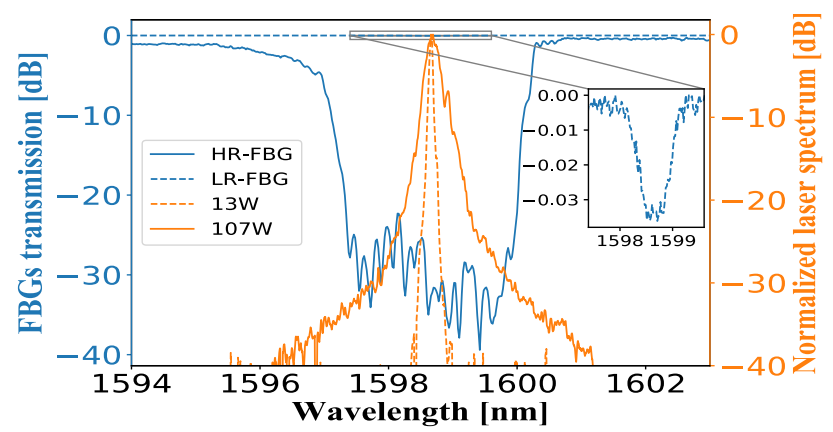

Fig. 3. Output spectrum of the laser superimposed on the transmission spectra of both FBGs written in the passive fibers.

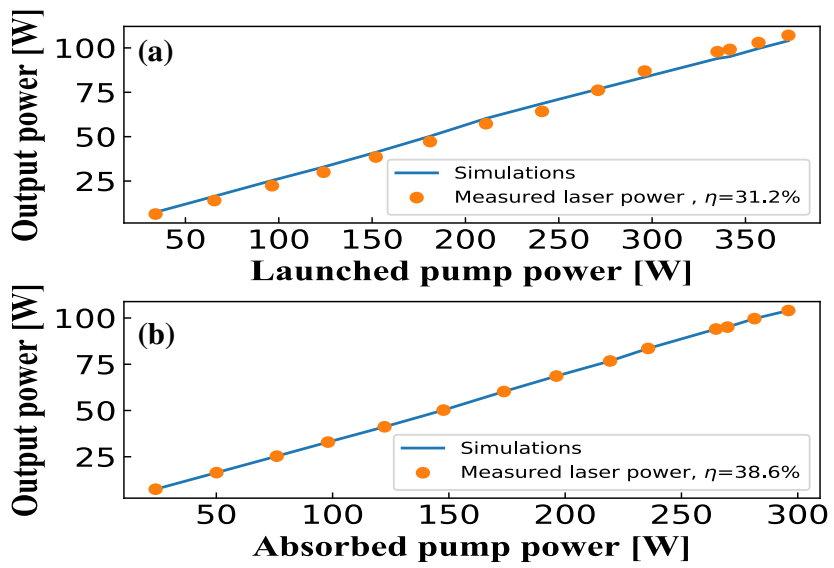

Fig. 4. Output power of the laser according to (a) launched pump power and (b) absorbed pump power.

pump power could also be improved by using an inner cladding Bragg grating (ICBG) [19] to recycle the residual pump power [20]. Moreover, results show no saturation of the laser signal at high power, suggesting that a higher output power could be achieved. For example, the use of a pump combiner with better specs in terms of maximum pump power per input fiber could increase the pump to $630 \mathrm{~W}$, instead of $420 \mathrm{~W}$, which would have resulted to approximately $160 \mathrm{~W}$ of laser power with the same setup.

In order to confirm the single-mode operation of the laser, the beam quality was characterized at an output power of $1.2 \mathrm{~W}$ with a $\mathrm{M}^{2}$ measurement setup (Nanoscan Pyro/9/5, Ophir Photonics), the results are shown in Fig. 5. This output power was chosen to avoid strong parasitic reflection in the cavity caused by the instrument, as well as to not damage the equipment. We measured a $\mathrm{M}^{2}$ for orthogonal axes of 1.09 and 1.12 respectively, which is approaching the minimum theoretical limit for a single-mode fiber $\left(\mathrm{M}^{2} \approx 1.03\right)$ [21].

A numerical model was developed in house in order to estimate the amount of paired ions in the fiber. This numerical model is the same as presented in [13], based on [22], and modified according to [23]. Multiple laser experiments using various fiber lengths as well as a thorough spectroscopic analysis of the core glass were performed to confirm the model's validity. These simulations matching the experimental results are then used to estimate the pump losses through upconversion. With this model, we estimated that the amount of paired ions was 5\%. Such occurrence of paired ions in the core glass matrix is lower than that of our previous study (6.3\% in [13]) having about $2-3$ times lower concentration of aluminum and phosphorus. This
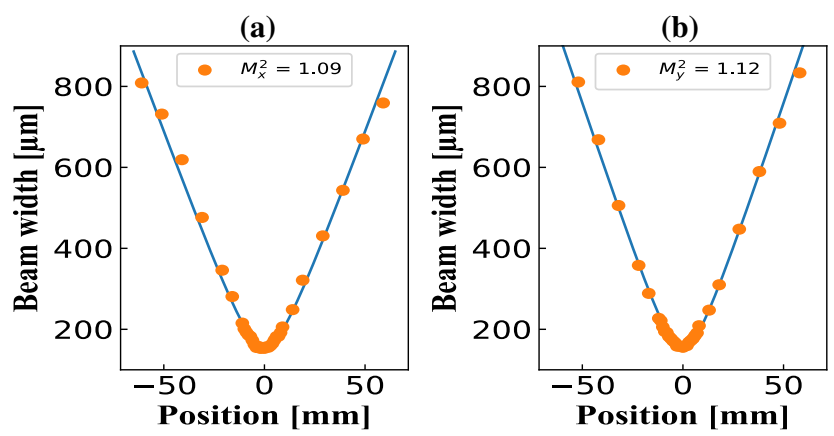

Fig. 5. Beam divergence in both (a) the $x$ axis and (b) the $y$ axis. 


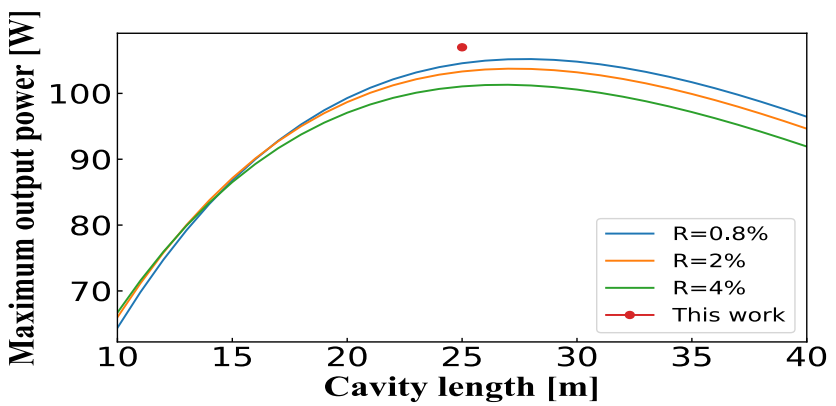

Fig. 6. Predicted maximum power of the laser for different cavity lengths.

numerical model was used to estimate the optimal length for the cavity as well as the optimal reflectivity of the output coupler. The optimization results are shown in Fig. 6. An optimal cavity length that achieve the maximum output power is around $27 \mathrm{~m}$, and the reflectivity of the output FBG should be as low as possible. Even though we would expect it to be superimposed onto the $\mathrm{R}=0.8 \%$ curve, the point representing our result is above this curve because the simulations tend to underestimate the output power at high pump powers. This $3 \%$ discrepancy could be explained by the spectral broadening in the laser cavity at high power (see Fig. 3), which further reduces the output coupler effective reflectivity, therefore optimizing the laser efficiency. This could explain the slightly increased laser efficiency at high power (see Fig. 4), as the spectral broadening occurring at high intensity become significant.

In conclusion, we demonstrate an Er-Ce co-doped all-fiber laser with a large concentration of $\mathrm{Al}_{2} \mathrm{O}_{3}$ and $\mathrm{P}_{2} \mathrm{O}_{5}$ in the core glass that generates $107 \mathrm{~W}$ of output power at $1598 \mathrm{~nm}$. The slope efficiency is $31.2 \%$ and $38.6 \%$ according to the launched and absorbed pump powers, respectively. The laser beam quality is excellent $\left(\mathrm{M}^{2} \leq 1.12\right)$, confirming a single-mode laser operation. Numerical modeling showed that the incorporation of aluminum and phosphorus ions at high concentration causes a reduction of paired ions, thus improving significantly the laser performances. Overall, this all-fiber design generated the highest output power in its category, while also being easier to manufacture.

Funding. Natural Sciences and Engineering Research Council of Canada (CRDPJ-543631-19, RGPIN-2016-05877); Fonds de Recherche du Québec Nature et Technologies; Canada Foundation for Innovation.

Acknowledgment. This research was performed at Université Laval as part of a graduate course (PHY-7052, laboratoire de photonique avancée) taking place during one semester at the department of Physics, Engineering Physics, and Optics. The authors would like to thank Stephan Gagnon, Patrick Larochelle, Vincent Fortin, Yigit Ozan Aydin, and Lauris Talbot for technical assistance.

Disclosures. The authors declare no conflicts of interest.
Data Availability. Data underlying the results presented in this paper are not publicly available at this time but may be obtained from the authors upon reasonable request.

${ }^{\dagger}$ These authors contributed equally to this work.

\section{REFERENCES}

1. J. K. Franks, in Eyesafe Lasers: Components, Systems, and Applications, A. M. Johnson, ed. (International Society for Optics and Photonics SPIE, 1991), vol. 1419, pp. 2-8.

2. H. Elgala, R. Mesleh, and H. Haas, IEEE Commun. Mag. 49, 56 (2011).

3. R. Frehlich, S. M. Hannon, and S. W. Henderson, Appl. Opt. 36, 3491 (1997).

4. Y. Zhang, M. Zhang, W. Jin, H. Ho, M. Demokan, X. Fang, B. Culshaw, and G. Stewart, Opt. Commun. 234, 435 (2004).

5. D. Y. Shen, J. K. Sahu, and W. A. Clarkson, Opt. Express 14, 6084 (2006).

6. Y. Jeong, S. Yoo, C. A. Codemard, J. Nilsson, J. K. Sahu, D. N. Payne, R. Horley, P. W. Turner, L. Hickey, A. Harker, M. Lovelady, and A. Piper, IEEE J. Sel. Top. Quantum Electron. 13, 573 (2007).

7. W. Yu, P. Yan, Q. Xiao, T. Qi, D. Li, and M. Gong, Appl. Opt. 60, 2046 (2021).

8. M. A. Jebali, J.-N. Maran, and S. LaRochelle, Opt. Lett. 39, 3974 (2014).

9. H. Lin, Y. Feng, Y. Feng, P. Barua, J. K. Sahu, and J. Nilsson, Opt. Lett. 43, 3080 (2018).

10. L. V. Kotov, M. E. Likhachev, M. M. Bubnov, O. I. Medvedkov, M. V. Yashkov, A. N. Guryanov, J. Lhermite, S. Février, and E. Cormier, Opt. Lett. 38, 2230 (2013).

11. L. V. Kotov, M. E. Likhachev, M. M. Bubnov, O. I. Medvedkov, M. V. Yashkov, A. N. Guryanov, S. Février, J. Lhermite, and E. Cormier, Proc. SPIE 8961, 89610X (2014).

12. M. E. Likhachev, M. M. Bubnov, K. V. Zotov, D. S. Lipatov, M. V. Yashkov, and A. N. Guryanov, Opt. Lett. 34, 3355 (2009).

13. M.-P. Lord, L. Talbot, O. Boily, T. Boilard, G. Gariépy, S. Grelet, P. Paradis, V. Boulanger, N. Grégoire, S. Morency, Y. Messaddeq, and M. Bernier, Opt. Express 28, 3378 (2020).

14. L. V. Kotov, M. E. Likhachev, M. M. Bubnov, O. I. Medvedkov, D. S. Lipatov, N. N. Vechkanov, and A. N. Guryanov, Quantum Electron. 42, 432 (2012).

15. M. Engholm, P. Jelger, F. Laurell, and L. Norin, Opt. Lett. 34, 1285 (2009).

16. K. E. Mattsson, Opt. Express 19, 19797 (2011).

17. T. Robin, T. Gotter, A. Barnini, P. Guitton, R. Montron, G. Mélin, C. Ranger, A. Laurent, and B. Cadier, Proc. SPIE 10528, 1052815 (2018).

18. M. Bernier, F. Trépanier, J. Carrier, and R. Vallée, Opt. Lett. 39, 3646 (2014).

19. L. Talbot, L.-C. Michaud, V. Boulanger, P. Paradis, and M. Bernier, Proc. SPIE 11261, 112610R (2020).

20. L. Talbot, P. Paradis, and M. Bernier, Opt. Lett. 44, 5033 (2019).

21. L. Li and F. Guo, Chin. Opt. Lett. 7, 106 (2009).

22. L.-P. Pleau, P. Paradis, J.-S. Freniére, M. Huneault, S. Gouin, S. M. Aljamimi, Y. O. Aydin, S. Duval, J.-C. Gauthier, J. Habel, F. Jobin, F. Maes, L.-R. Robichaud, N. Grégoire, S. Morency, and M. Bernier, Opt. Express 26, 22378 (2018).

23. J. Nilsson, B. Jaskorzynska, and P. Blixt, in Optical Amplifiers and Their Applications (Optical Society of America, 1993), p. MD19. 